\title{
Eating disorders and psychosis: a review and case report
}

Rita Almeida Leite

(iD) Tiago Santos ${ }^{1}$

iD Patrícia Nunes²

(iD) Isabel Brandão²

1. Department of Psychiatry and Mental Health, Baixo Vouga Hospital Centre, Aveiro, Portugal 2. Psychiatry and Mental Health Clinic, São João University Hospital Centre, Porto, Portugal

\section{SUMMARY}

INTRODUCTION: The interplay between eating disorders and psychosis is a challenging field to which little attention has been paid. Its study raises conceptual and methodological questions in both areas, making the diagnosis and management of patients difficult. Such questions are addressed and illustrated with a review and case report.

METHODS: The authors present the case of a woman with Anorexia Nervosa and with comorbid Shared Psychotic Disorder, based on a literature review regarding the comorbidity between eating disorders and psychosis. The authors conducted a non-systematic review by searching the PubMed database, using the Mesh Terms "anorexia nervosa", "bulimia nervosa", "comorbidity" and "psychotic disorders".

RESULTS: The findings suggest that studies on the subject are limited by issues regarding data on the prevalence of comorbidities, phenomenological aspects of eating disorders, and the interface and integration with psychotic symptoms.

CONCLUSIONS: The case presented illustrates the difficulties in managing a patient with a comorbid eating disorder and psychosis. In order to ensure a rigorous assessment of both psychotic and eating disorder symptoms, the focus should be on the pattern of appearance or emergence of symptoms, their phenomenology, clinical and family background of the patient, and clinical status on follow-up.

KEYWORDS: Anorexia nervosa. Comorbidity. Schizophrenia, paranoid. Psychotic disorders. Feeding and eating disorders. Shared paranoid disorder.

\section{INTRODUCTION}

The comorbidity between eating disorders (ED) and psychosis remains a subject of insufficient study. Reports exist since Bleuler in 1911, who described cases of schizophrenia with disordered eating related to delusional ideas. Particular disturbances, such as potomania, merycism, and pica have been often described in these patients, with variable degrees of severity ${ }^{1}$. Psychotic episodes are reported in 10-15\% of
ED patients, most of them transient, although 3-10\% will suffer from schizophrenia ${ }^{2,3}$. However, reports of comorbid schizophrenia and anorexia nervosa (AN) are scarce, and a significant number has been questioned on the basis of insufficient descriptions or lack of rigorous diagnostic criteria ${ }^{4,5}$. More recently, other authors have reported cases of comorbid AN and schizophrenia $^{6-12}$. Studies reporting comorbid bulimia 
nervosa and schizophrenia are even more scarce. The existing literature refers to case reports or studies with small series of patients $\mathbf{s}^{4,5,13-15}$. However, questions remain regarding the nature of the symptoms described and the diagnoses proposed.

\section{METHODS}

The authors report the case of a woman with a clinical history of AN previously treated at the age of 14 , who developed a new episode at the age of 32 , with comorbid Shared Psychotic Disorder. This study was based on a literature review regarding the comorbidity between eating disorders and psychosis. The authors conducted a non-systematic review by searching the PubMed database, using the Mesh Terms "anorexia nervosa", "bulimia nervosa", "comorbidity" and "psychotic disorders". The reviewed articles were selected according to their relevance. Some articles were also included from the references of the previously selected bibliography.

\section{DESCRIPTION}

This is the case of a 33-year-old single woman, who will be addressed as Mrs. S.

Mrs. S had no psychiatric background up until the age of 13, when she started to show an excessive concern with her body weight. She restricted her diet until it only included fruit and yogurts. Mrs. S. lost weight gradually, and at the time of her first admission, she presented severe restriction of caloric intake due to a morbid fear of getting fat, with a Body Mass Index (BMI) of $12.1 \mathrm{kgs} / \mathrm{m}^{2}$, without binge eating or compensatory behaviors such as self-induced vomiting or use of laxatives or diuretics. She was diagnosed with AN, of the restrictive type. She was admitted to an eating disorder treatment program (first being hospitalized, and then followed-up in an outpatient clinic) and became fully recovered with a BMI of 19 $\mathrm{kgs} / \mathrm{m}^{2}$. Then, Mrs. S. suspended follow-up until one month prior to the current hospital admission. She was admitted again due to a BMI of $11,7 \mathrm{kgs} / \mathrm{m}^{2}$. Both Mrs. S. and her family reported a normal weight until two years previously.

Her educational and family histories were assessed. Mrs. S. attributes her first episode of AN to her cousins since she was perfectly convinced she had been through some kind of spell, a perspective corroborated by her mother.
Mrs. S. went to Law School, as "I suffered from injustice throughout my life."

After finishing university, Mrs. S. applied to an elite estate institute for judges and public prosecutors. Before the final evaluation, she was told that she had failed due to an unsatisfactory performance during training. Mrs. S. believes that this was due to the fact they had discovered her disease when she was 14 "they probably secretly investigated my Hospital records..."

After leaving the institute, Mrs. S. refers that the problems continued "they broke into my house and searched my computer...” She believes that apparently ordinary people with whom she crosses on the street are involved in her surveillance "they look at me in a different way..."

Mrs. S's mother supports every statement, adding that "there are people disguised as tourists taking pictures..." Her mother looks insecure and avoids giving further details because of what may happen if she does. Mrs. S's father is less sure of this conspiracy theory, although stating that "it became necessary to change her house locks...”

During her developmental and social history assessment, Mrs. S. refers that she never had close friends, partners, or even family beyond the nuclear family since she feels insecure and mistrusted. Her mother always supported her. On the contrary, her father doesn't believe in that interpersonal mistrust, keeping friendly contacts.

There are no significant psychiatric antecedents in the family. Mrs. S's mother doesn't agree to her own psychiatric examination, neither to any kind of treatment.

As an inpatient, Mrs. S. remains reserved, circumspect, and expresses doubts about being watched: "there are cell phones... and we don't know if they are recording our conversations at this time...” She doesn't accept any antipsychotic medication.

The clinical case is resumed in Figure 1.

\section{DISCUSSION}

Concerning her eating behavior, the patient presents a restrictive type, with the first episode at the age of 13 and a recurrence when she was 31 years old. In the inter-critic period, the BMI was within normal range and no disturbed eating behavior was noticed.

Besides disturbances in eating behavior, the patient shows traits of a sensitive paranoid personality type, 


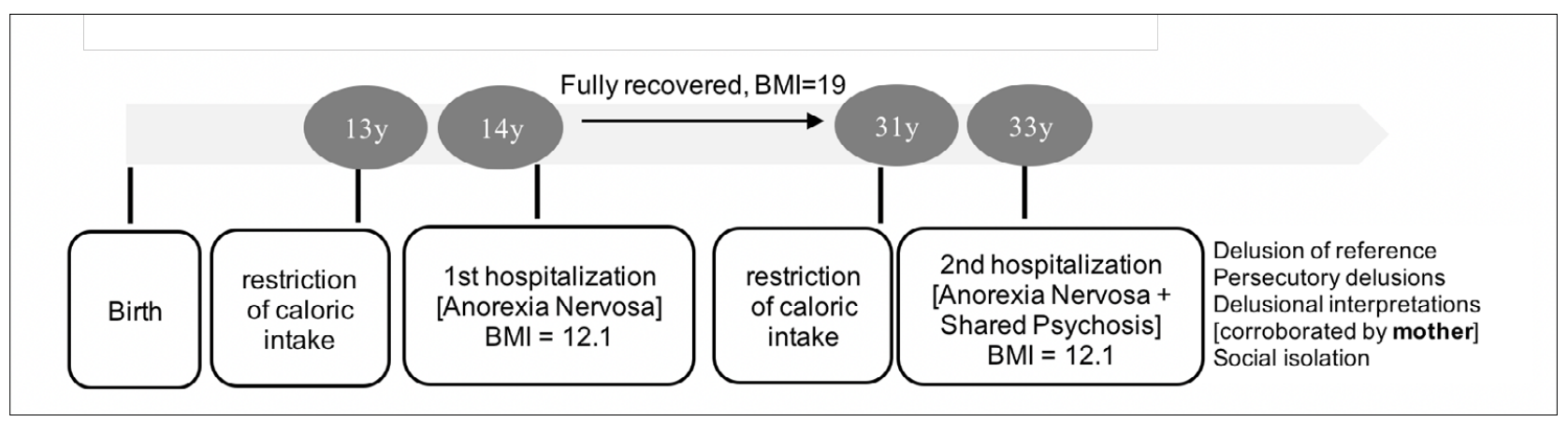

with a constant pattern of suspicion and distrust towards others. A peculiar sense of justice built on the idea that people around the patient are set to harm and conspire against her determined her path to law school.

The distrust and the scrutiny of the loyalty of those surrounding the patient progressively narrowed her social and family network. During the first episode of AN, the family reaction was to restrict contact with other members, as if they were part of the illness. The patient describes this movement as a crucial part of the recovery.

In the current episode, a type of rigid process of thinking evolves into a clinical picture compatible with a diagnosis of Delusional Disorder. The patient presented a delusional belief that she was the victim of a conspiracy with the intent of stopping her law career. With time and new experiences, these delusional beliefs became more solid and structured, in a clear continuum with previous personality traits, evidencing the constitutional organization of the delusional thought. Despite the direct impact of the delusional ideas, the patient maintained her previous levels of functioning, without any strange or bizarre behavior.

The delusional ideas were shared in full by the patient's mother, suggesting a Shared Delusional Disorder. This entity was first described by Laségue and Falret, under the designation of "folie à deux", in which there is a transference of delusional ideas from one individual to one or more people of close relations. People sharing delusional beliefs are usually relatives (close relatives and spouses in $97 \%$ of cases) who lived together for long periods of time, often in relative social isolation ${ }^{16}$.

In the case presented, all these premises are present, with a highly fusional mother-daughter relationship. This pattern is also common among families of patients with AN, along with the agglutination of their members, exaggerated repercussions of events in the family system, overprotection, rigidity, and difficulty in conflict resolution. Such characteristics, present in the patient's family, equally provide fertile ground to the development of a shared delusional disorder.

The case presented illustrates the difficulties in the diagnosis of these patients. Issues concerning the

TABLE 1. THE PREVALENCE OF PSYCHOSIS IN SAMPLES OF PATIENTS WITH EATING DISORDERS (ED)

\begin{tabular}{|c|c|c|c|c|}
\hline Author & $\begin{array}{l}\text { Year of } \\
\text { publication }\end{array}$ & $\begin{array}{l}\text { Number of } \\
\text { Subjects }\end{array}$ & $\begin{array}{l}\text { Comorbidity between } \\
\text { psychosis and ED }\end{array}$ & Other comments \\
\hline Foulon ${ }^{1}$ & 2003 & $N=75$ & Below 10\% & Reaches 35\% in males, the most frequent form being hebephrenia \\
\hline Hudson et al. ${ }^{4}$ & 1984 & $\begin{array}{l}\mathrm{N}=130 \\
\text { (anorexia or } \\
\text { bulimia) }\end{array}$ & $12 \%$ & $\begin{array}{l}16 \text { patients had psychotic symptoms attributed to an affective } \\
\text { disorder or a schizoaffective disorder, } \\
\text { none strictly responding to schizophrenia }\end{array}$ \\
\hline David et al. ${ }^{13}$ & 1986 & & Below 10\% & \\
\hline $\begin{array}{l}\text { Ferguson and } \\
\text { Damluji }\end{array}$ & 1988 & $N=200$ & $6 \%$ & $\begin{array}{l}\text { Reported other references such as Dally } \\
\text { (1969) 1\%; Theander (1970) 1\%; Hsu et al (1979) 3\% and (1981) 6\% } \\
\text { (3\% acute and transient during weight gain, 3\% schizophrenic); } \\
\text { Farquharson and Hyland (1966) 7\%; and Silverman (1977) 29\%. }\end{array}$ \\
\hline Steinhausen ${ }^{\mathbf{1 8}}$ & 2002 & $\begin{array}{l}119 \text { series, } \\
N=5590\end{array}$ & $4.6 \%$ & Reported that schizophrenia was rarely observed at follow-up \\
\hline Shiraishi et al. ${ }^{19}$ & 1992 & $N=55$ & $14 \%$ & \\
\hline $\begin{array}{l}\text { Striegel-Moore } \\
\text { et al. }{ }^{\mathbf{2 0}}\end{array}$ & 1999 & $\begin{array}{l}\mathrm{N}=98(\mathrm{ED}, \\
\text { men) }\end{array}$ & $\begin{array}{l}36 \%(\mathrm{AN}) \\
18 \%(\mathrm{BN})\end{array}$ & $\begin{array}{l}\text { Men with AN were at high risk for comorbid } \\
\text { psychosis, men with BN were at risk for comorbid personality } \\
\text { disorder. }\end{array}$ \\
\hline
\end{tabular}


interplay between symptoms of the psychotic spectrum and disordered eating are particularly challenging, as well as the nature of symptoms of ED.

Prevalence of comorbid Psychosis and Eating Disorders

Studies addressing the relationship between psychosis and ED show conflicting results, which are addressed in Table 1.

One of the factors contributing to these differences is that little is known about the comorbidity of psychiatric disorders among each other, of the accurate comorbidity with eating disorders specifically, and about sequential patterns across time ${ }^{18}$. Another aspect that confuses the numbers on prevalence is the lack of rigorous diagnostic criteria and symptom assessment, which can contribute to a higher number of cases found ${ }^{2,3}$.

\section{Comorbid Psychosis Versus Comorbid Eating Disorder}

The study of the sequential pattern of appearance of both psychotic and ED on each patient may contribute to the disclosure of some of the diagnostic difficulties.

Little doubt remains about the diagnosis of schizophrenia when cases refer to patients with a prior ED who develops full-blown psychotic symptoms ${ }^{3,13}$. A rupture in the personal biography occurs, conditioned by delusional ideas, which may partially overrun symptoms of the pre-existing ED.

On the other hand, two main studies conducted with samples of chronic schizophrenic patients show that they often demonstrate maladaptive eating attitudes $^{8,21}$. However, these attitudes are substantially different from the symptoms presented by typical ED patients. They are frequently seen in the context of delusional ideas or hallucinatory experiences, and the BMI is usually within the normal range. Although patients may show a fear of becoming fat and other concerns regarding body image, they seldom take notice of the caloric content of food or manifest the obsessional pattern of behavior characteristic of ED patients ${ }^{21}$. These aspects lead to the conclusion that patients with chronic schizophrenia may present disordered eating of an AN-like quality, although a distinct form compared with classic ED patients ${ }^{8,21}$.

Adding to these findings, the elderly are susceptible to demonstrating nutritional deterioration and substantial changes in eating habits, a condition often described as "anorexia tarda", associated with living conditions and cognitive decline, and in any case related to the pattern seen in ED patients ${ }^{8,22}$.

Other studies present case reports of disordered eating in schizophrenic patients ${ }^{3,6}$. The symptoms presented have a clinical background of delusional ideas and disordered behavior.

However, questions emerge in studies describing cases of young patients that present both psychotic and ED symptoms. We support that these difficulties are due to an erroneous attribution of a psychotic nature to ED symptoms, and to the use of ED diagnostic criteria regardless of the context of each particular case.

\section{Eating Disorder Symptoms Versus Psychotic} Symptoms

Several authors have proposed different hypotheses for comorbid psychotic and ED symptoms, resumed in Table 2.

One possibility is that ED and psychosis may represent different phenotypes of the same illness process $^{13,23}$. This hypothesis is supported by cases in which the symptoms of the pre-existing ED are overrun by the psychotic process, or in which the psychotic symptoms fluctuate inversely over time with the ED symptoms. The conclusion is that the ED symptoms can be attributed to the cognitive impairments resulting from the schizophrenic process and that would eventually lead to manifestations of psychosis ${ }^{23}$. In the same way, concerns about eating and body image may be seen as overvalued ideas, and therefore a relevant component of the psychotic process ${ }^{17}$. However, as referred earlier, studies available show no overrepresentation of schizophrenia in patients with ED or their families.

Curiously, the same arguments which are used to sustain the phenotype hypothesis are also used to support the hypothesis of disordered eating as a defense against psychosis, ${ }^{3,5,13}$. ED symptoms are considered to produce marked psychological stress and therefore can give rise to psychotic symptoms. This rationale presents several conceptual and methodological limitations.

TABLE 2. DIFFERENT HYPOTHESES PROPOSED FOR COMORBID PSYCHOSIS AND EATING DISORDERS (ED)

ED and Psychosis may represent different phenotypes of the same
illness process.
ED may be a defense against Psychosis.
Psychosis recurs because of the distress induced by the treatment
of ED symptoms.


On the other hand, the compensatory fluctuation of psychotic and ED symptoms seen in some cases is also regarded as a dynamic interaction in which psychosis recurs because of the distress induced by the treatment of ED symptoms. These considerations are sustained despite the fact that in the cases mentioned the fluctuation of symptoms was observed in parallel with the discontinuation of antipsychotics ${ }^{3,5,13}$.

Contents related to eating behavior are frequently present in delusional and hallucinatory activity, and hypothetically more in cases with a previous or comorbid ED, although the few cases described are insufficient to confirm this. However, the assumption that psychotic symptoms may be protective against the disorganization caused by the ED symptoms is just as accurate as affirming the exact opposite. On the other hand, ED symptoms in the context of a psychotic syndrome do imply a clinical and management profile of a different nature compared to typical EDs ${ }^{8,21}$.

\section{Psychotic Disorders Versus Eating Disorders}

An important issue in the discussion of co-morbid ED and psychotic symptoms, besides the possibility of co-occurrence of fluctuation over time, is the correct distinction between the two entities. Descriptions offered in studies of patients with comorbid psychotic and ED features raise questions about the nature of the symptoms presented ${ }^{2,3,9,11,17}$.

Patients with ED, in particular with low weight, may present with a pressure of speech, circumstantiality, and other forms of disordered speech, as well as labile or angry affect, among others. The ways these patients describe their bodily experiences and the constant focus on food and body weight, particularly with lower weights, are easily taken for somatic delusions. Authors such as Ferguson and Damluji ${ }^{17}$ in a series of 12 patients, in the absence of consistent delusional or hallucinatory activity, classified them as suffering from AN and schizophrenia of the disorganized type. The symptoms present were interpreted as evidence of the negative dimension of schizophrenia and related to deficits of functioning.

Another author also describes two cases of patients diagnosed with AN who manifested psychotic symptoms ${ }^{10}$. The author makes equal assumptions regarding symptoms that, to our view, are not to be excluded as features of an ED. It is striking how psychotic symptoms do not seem to be consistent, remit in a short period of time without the use of antipsychotics, and are focused on bodily experiences.
Cinemre and Kulaksizoglu ${ }^{11}$ describe a patient diagnosed with AN who later developed schizophrenia. Some questions arise regarding the diagnostic proposal. The authors describe a 18 -year-old male patient with a 4-year period prior to a full-blown schizophrenic crisis characterized by disordered eating and odd behavior regarding weight and body image, without reaching an abnormal BMI.

\section{CONCLUSIONS}

The comorbidity between eating disorders and psychosis is infrequent and raises several conceptual and methodological questions. Epidemiological and family studies show that there is no more significant association between schizophrenia and ED, although these results are somehow limited by the lack of rigorous data regarding ED.

The existence of ED symptoms in schizophrenic patients and in elderly patients with cognitive deterioration is well documented, as well as the organization of symptoms, which makes it distinct from the classic ED diagnosis.

It is important to determine the sequential pattern of appearance of the symptoms and to make a rigorous assessment of their nature. Many ED symptoms, in particular with a low and very low BMI, may resemble psychotic features. Symptoms must be contextualized while simultaneously avoiding tempting interpretations of ED or psychotic features.

The case presented described a patient with AN and comorbid delusional disorder and shared psychotic disorder. The patient's delusional thought was coherent, with a developmental course and susceptible personality traits. In addition, her parent's involvement, in particular her mother, in full-blown shared psychosis, is consistent with what is known about the characteristics of families of patients with AN. In fact, the reaction and the solution found within the family to the first episode of AN may have accentuated the pre-existing personality and functioning features of the patient. Later in life, an intense distressful event, included in the main theme of her delusional thought, triggered a new stage of AN. This process took place without any degree of disorganization or deficit and exhibiting all features of AN. The sharing of psychotic beliefs is a demonstration of the level of agglutination among family members, overprotection, and of the high sensitivity and repercussion events have in the family system, simultaneously present in ED patients' families. 
The case presented and the review on the subject point out the importance of defining the context of symptom presentation, its rigorous phenomenology, and the course of the illness for a correct assessment and diagnosis, as well as further investigation of the relationship between psychotic and eating disorders.

\section{Author's Contribution}

Rita Almeida Leite: Planning of the publication, drafting of the project, definition of strategies and steps, bibliographic search in medical databases, and drafting of the paper.

Tiago Santos: Supported the planning of the publication and drafting of the project, guided the bibliographic search, drafted the clinical case, and revised the text in English.

Patrícia Nunes: Participated in the drafting of the clinical case, revised the bibliographic search, the draft of the papers, and the text in English.

Isabel Brandão: Revise the entire text of the clinical case and the final text of the paper.

\section{RESUMO}

INTRODUÇãO: A interface entre perturbação do comportamento alimentar e psicose é um campo desafiador para o qual pouca atenção foi direcionada. O seu estudo levanta algumas questões conceituais e metodológicas em ambas as áreas, dificultando o diagnóstico e o manejo dos pacientes. Essas questões são abordadas e ilustradas neste trabalho com uma revisão e um relato de caso.

MÉTODOS: Os autores apresentam o caso de uma mulher com anorexia nervosa e perturbação psicótica partilhada comórbida, com base numa revisão da literatura sobre a comorbilidade entre perturbação do comportamento alimentar e psicose. Os autores realizaram uma revisão não sistemática, por meio de pesquisa no banco de dados PubMed, utilizando os termos "anorexia nervosa", "bulimia nervosa", "comorbilidade" e "perturbações psicóticas".

RESULTADOS: Os resultados sugerem que os estudos sobre o tema são limitados por questões inerentes a escassos dados sobre prevalência de comorbilidades, aspectos fenomenológicos das perturbações alimentares, e sua interface e integração com sintomas psicóticos.

CONCLUSÕES: O caso apresentado ilustra as dificuldades no manejo de uma paciente com perturbação alimentar e psicose. A fim de garantir uma abordagem rigorosa dos sintomas psicóticos e alimentares, a avaliação do paciente deve focar o padrão de emergência dos sintomas, a sua fenomenologia, antecedentes clínicos e familiares e o seu status clínico.

PALAVRAS-CHAVE: Anorexia nervosa. Comorbidade. Esquizofrenia paranoide. Transtornos psicóticos. Transtornos da alimentação e da ingestão de alimentos. Transtorno paranoide compartilhado.

\section{REFERENCES}

1. Foulon C. Schizophrenia and eating disorders. Encephale. 2003;29(5):463-6.

2. Sarró $S$. Transient psychosis in anorexia nervosa: review and case report. Eat Weight Disord. 2009;14(2-3):139-43.

3. Seeman MV. Eating disorders and psychosis: seven hypotheses. World J Psychiatry. 2014;4(4):112-9.

4. Hudson JI, Pope HG Jr, Jonas JM. Psychosis in anorexia nervosa and bulimia. Br | Psychiatry. 1984;145:420-3.

5. Deckelman MC, Dixon LB, Conley RR. Comorbid bulimia nervosa and schizophrenia. Int J Eat Disord. 1997;22(1):101-5.

6. Cheung P, Wilder-Smith E. Anorexia nervosa and schizophrenia in a male Chinese. Int J Eat Disord. 1995;18(1):103-6.

7. Hugo P|, Lacey |H. Disordered eating: a defense against psychosis? Int | Eat Disord. 1998;24(3):329-33.

8. Muñoz CE, Ryan WG. Late-onset anorexia nervosa in schizophrenia: a case report. Ann Clin Psychiatry. 1997;9(2):109-11.

9. Dymek M, le Grange D. Anorexia nervosa with comorbid psychosis and borderline mental retardation: a case report. Int J Eat Disord. 2002;31(4):478-82.

10. Stein D, Zemishlani C, Shahal B, Barak Y. Disordered eating in elderly female patients diagnosed with chronic schizophrenia. Isr | Psychiatry Relat Sci. 2005;42(3):191-7.

11. Cinemre B, Kulaksizoğlu B. Case report: comorbid anorexia nervosa and schizophrenia in a male patient. Turk Psikiyatri Derg. 2007;18(1):87-91.

12. Kouidrat $Y$, Amad A, Lalau JD, Loas G. Eating disorders in schizophrenia: implications for research and management. Schizophr Res Treatment. 2014:2014:791573.

13. David AS, Farmer AE, Murray RM. Schizophrenia and bulimia: case report.
Int J Eat Disord. 1986;5(4):771-5.

14. Blinder B|, Cumella E], Sanathara VA. Psychiatric comorbidities of female inpatients with eating disorders. Psychosom Med. 2006;68(3):454-62.

15. Theisen FM, Linden A, König IR, Martin M, Remschmidt H, Hebebrand J. Spectrum of binge eating symptomatology in patients treated with clozapine and olanzapine. J Neural Transm (Vienna). 2003;110(1):111-21.

16. Arnone D, Patel A, Tan GM. The nosological significance of Folie à Deux: a review of the literature. Ann Gen Psychiatry. 2006;5:11.

17. Ferguson IM, Damluji NF. Anorexia nervosa and schizophrenia. Int | Eat Disord. 1988;7(3):343-52.

18. Steinhausen $\mathrm{HC}$. The outcome of anorexia nervosa in the $20^{\text {th }}$ century. Am J Psychiatry. 2002;159(8):1284-93.

19. Shiraishi H, Koizumi J, Suzuki T, Yamaguchi N, Mizukami K, Hori $M$, et al. Eating disorder and schizophrenia. Jpn j Psychiatry Neurol. 1992;46(4):859-67.

20. Striegel-Moore RH, Garvin V, Dohm FA, Rosenheck RA. Psychiatric comorbidity of eating disorders in men: a national study of hospitalized veterans. Int J Eat Disord. 1999;25(4):399-404.

21. Lyketsos GC, Paterakis P, Beis $A$, Lyketsos CG. Eating disorders in schizophrenia. Br J Psychiatry. 1985;146:255-61.

22. Ikeda M, Brown J, Holland AJ, Fukuhara R, Hodges JR. Changes in appetite, food preference, and eating habits in frontotemporal dementia and Alzheimer's disease. J Neurol Neurosurg Psychiatry. 2002;73(4):371-6.

23. Yamashita Y, Takei N, Kawai M, Mori N. Anorexia nervosa as a phenotype of cognitive impairment in schizophrenia. Br J Psychiatry. 1999;174:558. 